\title{
Evaluasi Intensitas Konsumsi Energi Listrik Kampus Politeknik Negeri Balikpapan
}

\author{
Hadiyanto $^{1^{*}}$, Suhaedi ${ }^{2}$, \\ ${ }^{1,2}$ Jurusan Elektronika, Politeknik Negeri Balikpapan \\ *hadiyanto@poltekba.ac.id
}

\begin{abstract}
Energy audit is a method used to determine the profile of energy use of buildings as well as to find out about efforts to save efficiency. However, the energy audit activity at the Balikpapan State Polytechnic has not been carried out on an ongoing basis for the needs of efficient use of electricity. The purpose of this study was to determine the profile of energy use, and the magnitude of the Energy Consumption Intensity and the level of efficiency in the Balikpapan State Polytechnic. The research method used was an analysis of the calculation of energy consumption intensity (IKE) for each part of the room. The results showed the power consumption in Balikpapan State Polytechnic in 2016 was $62.7 \mathrm{kWH}$ and the IKE level was 93,096 $\mathrm{kWH} / \mathrm{m}^{2} /$ year. The highest use of electrical energy consumption per year in the civil engineering building is $33.876 .38 \mathrm{kWH} /$ year, while the lowest building heavy equipment engineering workshop is $28.460,875 \mathrm{kWH} /$ year. This study provides recommendations that can be used by management to take strategic steps in saving electricity.
\end{abstract}

Keywords : Audit, Electric Energy, Electric Power, Energy Intensity

\begin{abstract}
Abstrak
Audit energi merupakan cara yang digunakan untuk mengetahui profil penggunaan energi bangunan gedung serta mengetahui upaya efiseinsi penghematanya. Namun,kegiatan audit energi di Politeknik Negeri Balikpapan belum dilaksanakan secara berkelanjutan untuk kebutuhan efesiensi penggunaan energi listrik.Tujuan penelitian untuk untuk mengetahui profil penggunaan energi, dan besarnya intensitas konsumsi energi serta tingkat efisiensi di Politeknik Negeri Balikpapan. Metode penelitian yang dilakukanmenggunakan analisa perhitungan intesitas konsumsi energi (IKE) untuk masing-masing bagian ruangan. Hasil penelitian menunjukan konsumsi daya di Politeknik Negeri Balikpapan pada tahun 2016 sebesar 62,7 kWH dan tingkat IKE sebesar 93,096 $\mathrm{kWH} / \mathrm{m}^{2} /$ tahun.Penggunaan konsumsi energi listrik pertahun yang paling tinggi digedung teknik sipil yaitu 33.876,38 $\mathrm{kWH} /$ tahun, sedangakan terendah gedung workshop teknik mesin alat berat sebesar $28.460,875 \mathrm{kWH} / \mathrm{tahun}$. Studi ini memberikan rekomendasi yang dapat digunakan oleh manajemen untuk mengambil langkah-langkah strategis dalam penghematan energi listrik.
\end{abstract}

Kata kunci : Audit, Energi Listrik, Daya Listrik, IKE

\section{Pendahuluan}

Energi mempunyai peranan penting dalam pencapaian tujuan sosial, pendidikan, dan lingkungan untuk pembangunan berkelanjutan, serta pendukung bagi kegiatan pendidikan nasional[1]. Kampus Politeknik
Negeri Balikpapan adalah salah satu lembaga yang memiliki ketergantungan tinggi terhadap kebutuhan energi listrik sebagai operasional.Namun pada kenyataannya proses audit energi masih jarang diterapkan di Indonesia, terutama bagi gedung gedung 
komersial seperti gedung perkantoran, sekolah, universitas, rumah sakit maupun gedunggedung komersial lainnya. Masalah kelistrikan timbul karena peningkatan pemanfaatan energi listrik akan mengakibatkan biaya tagihan meningkat [2,3]. Permasalahan lain adalah peningkatan pemakaian energi listrik yang tidak sebanding dengan peningkatan kapasitas energi listrik yang tersedia akan mengakibatkan gangguan seperti pemadaman, sekring meledak, stabilitas daya, dan lain lain[4,5]. Meningkatkan efisiensi energi sangat penting untuk mencapai kelestarian lingkungan [6]. Kebutuhan energi yang tinggi menuntut manajemen Politeknik Negeri Balikpapan melakukan efisiensi dalam penggunaannya. Oleh karena itu, diperlukan upaya audit energi untuk mencapai tujuan efisiensi energi yaitu mengidentifikasi besarnya konsumsi energi dan mengidentifikasi besarnya energi yang digunakan pada bagian-bagian operasionalnya, serta mencoba mengidentifikasi kemungkinan penghematan energi[7].

Penelitian tentang audit dan manajemen energi sudah banyak dilakukan mengingat potensi penghematan energi yang bisa diperoleh jika masyarakat melakukan pengelolaan energi secara baik dan berkelanjutan [6]. Penelitian tentang manajemen energi dilakukan di lembaga pendidikan oleh [7], yang memberikan hasil pengujian yang bahwa kondisi kelistrikan di gedung tidak memenuhi standar PUIL 2000, baik dari pengaturan beban dan sistem pemasangan instalasi listriknya. Penelitian lain oleh [6] tentang audit energi listrik hotel Sun Island Bali, studi ini menjelaskan bahwa penggunaan intensistas konsumsi gedung hotel sudah efisien karena dari hasil perhitungan IKE, hotel tempat penelitian mereka menujukkan konsumsi energi listrik sebesar 4,1 $\mathrm{kWH} / \mathrm{m}^{2} /$ bulan. Menurut ketentuan Standar Nasional Indonesia, penggunaan konsumsi energi listrik bangunan gedung dengan AC dikatakan sangatefisien bila nilai IKE sebesar $<8 \mathrm{kWh} / \mathrm{m}^{2} /$ bulan[4]. Oleh karena itu, dalam penelitian ini melakukan audit konsumsi energi listrik untuk sebuah gedung sektor perkantoran dalam rangka mendapatkan rata-rata pemakain listrik.

Pendekatan yang dilakukan dalam penelitian ini adalah dengan metode Intensitas Konsumsi Energi Listrik (IKE) yang merupakan parameter yang dijadikan pedoman perlu tidaknya dilakukan audit terhadap penggunaan energi pada gedung $[2,8]$. Penelitian ini melakukan tahapan pencatatan penggunaan energi secara sistematis dan berkesinambungan. Pengumpulan data kemudian diikuti dengan analisa dan pendefinisian kegiatan audit energi yang akan dilaksanakan. Politeknik Negeri Balikpapan memiliki satu trafo dengan kapasitas sebesar 104 kVA untuk menyuplai listrik untuk gedung rektorat, gedung elektro, dan gedung workshop teknik mesin dengan masing-masing gedung memiliki backup listrik ketika padam sebesar $90 \mathrm{kVA}$ untuk gedung gedung elektro, $90 \mathrm{kVA}$ untuk gedung rektorat, dan $90 \mathrm{kVA}$ untuk gedung workshop teknik mesin.

Tujuan penelitian ini untuk mengetahui profil penggunaan energi, dan besarnya Intensitas Konsumsi Energi serta tingkat efisiensi di Politeknik Negeri Balikpapan. Kontribusi penelitian ini adalah orientasi dalam pengembangan dan memperluas ilmu sistem tenaga listrik untuk dapat diaplikasikan pada banyak bidang, khususnya pada bidang manajemen kelistrikan dengan menggunakan standa IKE. Manfaat penelitian ini yattu memberikan pemahaman tentang penghematan energi, dimana kegiatan manajemen energi perlu dilakukan agar penggunaan energi terutama energi listrik menjadi lebih efisien.

\section{Metode Penelitian}

\subsection{Sampel dan Pengumpulan Data}

Penelitian dilakukan di Politeknik Negeri Balikpapan yang merupakan sektor perkantoran dengan pertimbangan : 1) lokasi tersebut berada disekitar objek penting beban listrik; 2) memiliki permasalahan krisis dan boros pemakaian energi listrik ; 3) memliliki potensi untuk efisiensi penggunan daya listrik. Lokasi terpilih adalah gedung Elektronika, 
gedung Rektorat, gedung Mesin.Ketiga gedung ini memiliki beban listik yang masa aktif 24 jam sehingga bermanfaat dalam pembacaan data secara real-time. Perangkat elektronik yang menjadi sampel dalam penelitian ini adalah lampu, AC, dan server data serta semua peralatan elektronik yang terhubung ke listrik PLN.Tahapan audit energi meliputi audit energi awal dan audit energi rinci yangdigunakan dalam proses pengambilan data. Langkah pengumpulan data yakni melakukan spesifikasi konsumsi energi pada peralatan elektronik, pengukuran kuat terang cahaya, danpengukuran arus pada beban AC. Gambar 1 berikut menunjukkan tahaptahap dalam penelitian ini.

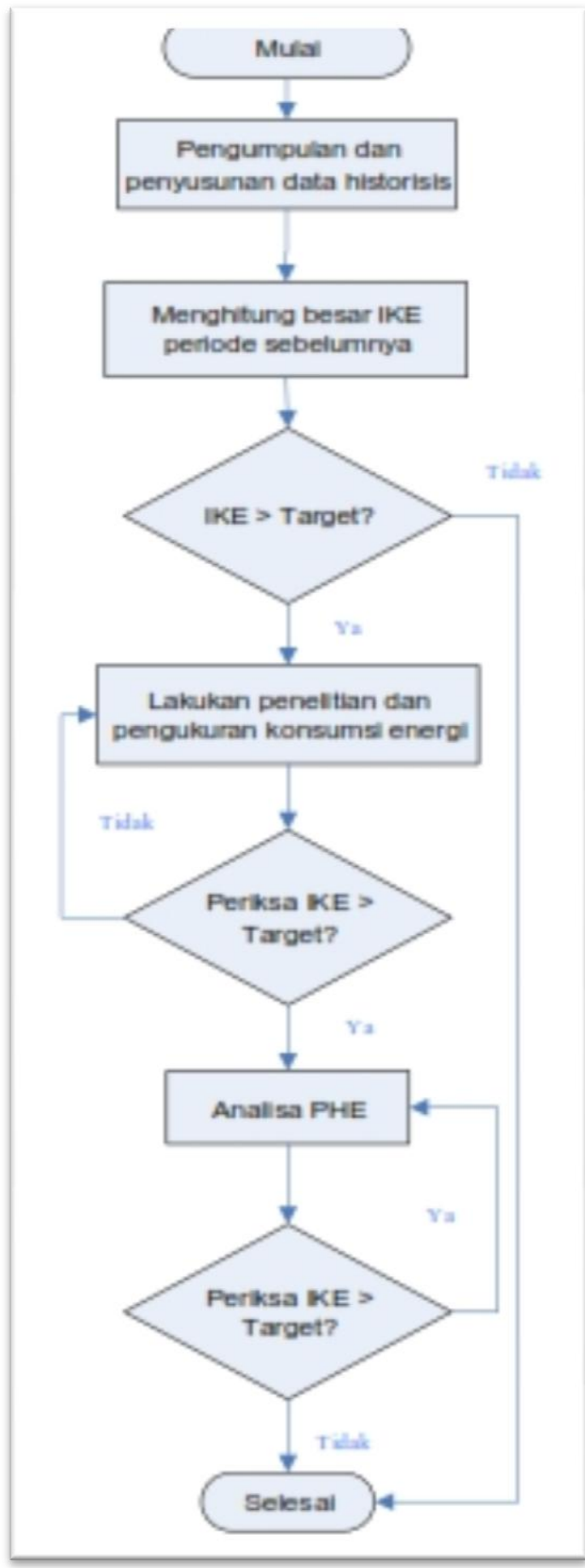

Gambar 1. Tahapan Penelitian

Studi ini menggunakan desain penelitian observasi lapangan (suvery). Teknik pengambilan data yaitu mengidentifikasi masalah dengan membandingkan data konsumsi energi beban yang diperoleh dari lapangan dengan nilai standar efisiensi IKE. Jika nilai IKE gedung lebih besar dari nilai standar IKE maka gedung tersebut mengalami 
permasalahan efisiensi energi maka perlu dilakukan perbaikan dan identifikasi IKE. Untuk menghitung nilai IKE maka diperlukan nilai total $\mathrm{kWH}$ dan luas gedung permeter persegi.Variabel yang diukur dalam penelitian ini adalah arus, tegangan, daya, dan energi.Prinsip pengukuran data adalah melihat data history energi untuk periode (bulan) sebelumnya, kemudian menghitung nilai IKE periode sebelumnya juga. Jika nilai IKE lebih besar dari target maka dilakukan pengukuran konsumsi energi listrik setiap gedung. Metode ini telah dilakukan oleh [6] yang dapat digunakan untuk evalusi daya listrik sebuah gedung sebagai rekomendasi penggunaan energi listrik.

\subsection{Analisi Data}

Setelah data konsumsi energi hasil pengukuran didapatkan, maka dilakukan analsis data dengan menghitung konsumsi energi listrik per tahun dan besar intensitas energi listrik. Rekomendasi usulan hasil penelitian dalam hal ini adalah tentang audit energi. Setelah melakukan pengumpulan data, identifikasi penggunaan energi, dan identifikasi standar IKE maka diperoleh data total pemakaian energi listrik Politeknik Negeri Balikpapan. Berdasarkan data tersebut dapat dijadikan sebagai dasar untuk menentukan rekomendasi PHE. Pengukuran mendapatkan nilai rata-rata intensitas konsumsi energi listrik Politeknik Negeri Balikpapan sebesar $62.700 \mathrm{kWH}$ setiap bulan sehingga setahun akan membutuhkan konsumsi energi listrik sebesar $752.400 \mathrm{kWH}$.

\section{Hasil Penelitian dan Pembahasan}

\subsection{Hasil Penelitian}

\subsubsection{Perhitungan Awal Audit}

Berdasarkan survei lapangan yang telah dilakukan, maka diperoleh beberapa data yang akan digunakann dalam proses perhitungan IKE (Indeks Konsumsi Energi) dilingkungan Politeknik Negeri Balikpapan. Perhitungan awal memerlukan data sekunder pemakaian energi listrik melalui tagihan listrik yang diberikan setiap bulannya. Sebagai informasi data tagihan listrik yang akan digunakan sebagai audit awal menggunakan data tagihan listrik selama 5 bulan mulai Mei sampai dengan September 2016.

Tabel 1. Intensitas Konsumsi Energi Listrik Politeknik Negeri Balikpapan

\begin{tabular}{cccc}
\hline No. & Bulan & Luas Gross & kWH \\
\hline 1 & Mei & 8082 & 85600 \\
2 & Juni & 8082 & 72100 \\
3 & Juli & 8082 & 55800 \\
4 & Agustus & 8082 & 48700 \\
5 & September & 8082 & 51300 \\
\hline
\end{tabular}

(Sumber: olahan data sekunder)

Sedangkan untuk mengetahui IKE setiap bulan dapat digunakan persamaanIKE.

$$
I K E=\frac{\text { Total } k W H \text { perbulan }}{\text { Luas Gross }}
$$

Tabel 2. Intensitas Konsumsi Energi Listrik Politeknik Negeri Balikpapan

\begin{tabular}{clccc}
\hline No. & Bulan & $\begin{array}{c}\text { Luas } \\
\text { Gross }\end{array}$ & kWH & IKE \\
\hline 1 & Mei & 8082 & 85600 & 10,59 \\
2 & Juni & 8082 & 72100 & 8,921 \\
3 & Juli & 8082 & 55800 & 6,904 \\
4 & Agustus & 8082 & 48700 & 6,025 \\
5 & September & 8082 & 51300 & 6,347 \\
\hline
\end{tabular}

(Sumber: olahan data primer)

Jika rata-rata intensitas konsumsi energi listrik sebesar $62.700 \mathrm{kWH}$ setiap bulan sehingga setahun akan membutuhkan konsumsi energi listrik sebesar $752.400 \mathrm{kWH}$. Berdasarkan data tersebut, makapada tahun 2016 IKE sebesar:93, $096 \mathrm{kWH} / \mathrm{m}^{2}$ pertahun.

\subsubsection{Pengukuran Energi}

Hasil pengukuran konsumsi daya untuk setiap ruangan dan lantai di beberapa Gedung diantaranya; 
Tabel 3. Konsumsi Daya di Ruangan Gedung Elektronika

\begin{tabular}{ccc}
\hline No & Ruangan & Konsumsi Daya \\
\hline 1 & R201 & 12.168 Watt \\
2 & R202 & 8.348 Watt \\
3 & R214 & 7.398 Watt \\
4 & R212 & 6.928 Watt \\
5 & R204 & 8.948 Watt \\
6 & R205 & 5.148 Watt \\
7 & R207 & 2.326 Watt \\
8 & R313 & 11.364 Watt \\
9 & R301 & 8.613 Watt \\
10 & R302 & 5.232 Watt \\
11 & R303 & 2.844 Watt \\
12 & R213 & 2.994 Watt \\
13 & R209 & 1.248 Watt \\
14 & R210 & 1.466 Watt \\
\hline \multicolumn{3}{c}{ Jumlah }
\end{tabular}

(Sumber: olahan data primer)

Berdasarkan Tabel 3, diperoleh bahwa jumlah konsumsi energi total perhari untuk gedung elektronika lantai 1 dan 2 diasumsikan sebesar 85,025 kWH. Dengan data tersebut data diperoleh perhitungan untukKonsumsi Energi Listrik per tahun adalah 31.034,125 $\mathrm{kWH} /$ tahun dan besar Intensitas Energi Listrik $12,0474 \mathrm{kWH} /$ tahun $/ \mathrm{m}^{2}$

Tabel 4. Konsumsi Daya di Gedung Rektorat

\begin{tabular}{|c|c|c|}
\hline No & Ruangan & Konsumsi Daya \\
\hline 1 & Lantai 1 & $36,620 \mathrm{~kW}$ \\
\hline 2 & Lantai 2 & $41,808 \mathrm{~kW}$ \\
\hline 3 & Lantai 3 & $8,234 \mathrm{~kW}$ \\
\hline & Jumlah & $86,662 \mathrm{~kW}$ \\
\hline
\end{tabular}

Berdasarkan Tabel 4, diperoleh bahwa jumlah konsumsi energi total perhari untuk gedung rektorat lantai 1, 2, dan 3 sebesar $86,662 \mathrm{kWH}$. Dengan data tersebut data diperoleh perhitungan untuk konsumsi energi listrik per tahun adalah 31.631,63 kWH/tahun dan besar intensitas energi listrik 13,358 $\mathrm{kWH} /$ tahun $/ \mathrm{m}^{2}$

Tabel 5. Konsumsi Daya di Ruangan Gedung TMAB

\begin{tabular}{|c|c|c|}
\hline No & Ruangan & Konsumsi Daya \\
\hline 1 & Lantai Utama & $77,975 \mathrm{~kW}$ \\
\hline & Jumlah & $77,975 \mathrm{~kW}$ \\
\hline
\end{tabular}

Berdasarkan Tabel 5, diperoleh bahwa jumlah konsumsi energi total perhari untuk gedung teknik mesin alat berat sebesar 77,975 kWH. Dengan data tersebut data diperoleh perhitungan untuk Konsumsi Energi Listrik per tahun 28.460,875 kWH/tahun dan Besar Intensitas Energi Listrik47,435 $\mathrm{kWH} /$ tahun $/ \mathrm{m}^{2}$.

Tabel 6. Konsumsi Daya di Ruangan Gedung Sipil

\begin{tabular}{ccc}
\hline No & Ruangan & Konsumsi Daya \\
\hline 1 & Lantai Utama & $92,812 \mathrm{~kW}$ \\
& Jumlah & $92,812 \mathrm{~kW}$ \\
\hline \multicolumn{2}{l}{ (Sumber: olahan data primer) }
\end{tabular}

Berdasarkan Tabel 6, diperoleh bahwa jumlah konsumsi energi total perhari untuk gedung teknik sipil sebesar 92,812 kWH. Dengan data tersebut data diperoleh perhitungan nergi listrik pertahun 33876,38 $\mathrm{kWH} /$ tahun dan Besar Intensitas Energi Listrik $56,46 \mathrm{kWH} / \mathrm{tahun} / \mathrm{m}^{2}$.

\subsection{Pembahasan}

Berdasarkan perhitungan diatas, dapat kita lihat bahwa untuk intensitas konsumsi energi (IKE) listrik di Politeknik Negeri Balikpapan pada tahun 2016 berada pada level 93,096 kWH/m²/tahun. Berdasarkan standar Intensitas Konsumsi Energi (IKE) listrik untuk Indonesia, maka IKE Politeknik Negeri Balikpapan tahun 2016 masih berada di bawah batas aman untuk gedung perkantoran yaitu $240 \mathrm{kWH} / \mathrm{m}^{2} /$ tahun.

Sedangkan secara umum penggunaan konsumsi energi listrik di linkungan Politeknik Negeri Balikpapan pada tahun 2016 rata-rata sebesar 62,7 kWH pertahun.

Untuk penggunaan konsumsi energi listrik untuk setiap gedung dilingkungan Politeknik Negeri Balikpapan dilakukan perhitungan harian dengan asumsi penggunaan peralatan listrik yang ada disetiap gedung dinyalakan serentak, sehingga akan diperoleh konsumsi energi listrik harian untuk setiap gedung[7].

Berdasarkan perhitungan tersebut, dapat dilihat bahwa konsumsi energi listrik harian untuk gedung elektronika pada lantai 1 dan 2 adalah sebesar 85,025 kWH/hari. Dengan data tersebut dapat diketahui konsumsi energi 
listrik untuk pertahun untuk gedung elektronika sebesar 31.034,125 kWH/tahun. Adapun intensitas konsumsi energi (IKE) listrik untuk gedung elektronika dengan luas gross sebesar $2.576 \mathrm{~m}^{2}$ adalah 12,047 $\mathrm{kWH} / \mathrm{m}^{2} /$ tahun.

Pada gedung rektorat berlantai 3, konsumsi energi listrik harian berdasarkan Tabel 4 adalah sebesar 86,662 kWH, Dengan data tersebut dapat diketahui konsumsi energi listrik untuk pertahun untuk gedung rektorat sebesar 31.631,63 kWH/tahun. Adapun IKE listrik gedung rektorat dengan luas gross

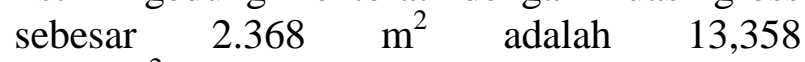
$\mathrm{kWH} / \mathrm{m}^{2} /$ tahun.

Untuk gedung workshop teknik mesin alat berat, konsumsi energi listrik harian berdasarkan Tabel 5 adalah sebesar 77,975 $\mathrm{kWH}$. Dengan data tersebut dapat diketahui konsumsi energi listrik untuk pertahun untuk gedung workshop teknik mesin alat berat sebesar 28.460,875 kWH/tahun. Adapun intensitas konsumsi energi (IKE) listrik untuk gedung workshop teknik mesin alat berat dengan luas gross sebesar $600 \mathrm{~m}^{2}$ adalah $47,435 \mathrm{kWH} / \mathrm{m}^{2} /$ tahun.

Pada gedung workshop teknik sipil, konsumsi energi listrik harian di gedung workshop teknik sipil berdasarkan Tabel 6 sebesar 92,812 kWH. Dengan data tersebut dapat diketahui konsumsi energi listrik untuk pertahun untuk gedung workshop teknik sipil sebesar 33.876,38 kWH/tahun. Adapun intensitas konsumsi energi (IKE) listrik untuk gedung workshop teknik sipil dengan luas gross sebesar workshop teknik sipil $\mathrm{m}^{2}$ adalah $56,46 \mathrm{kWH} / \mathrm{m}^{2} /$ tahun.

Penggunaan energi listrik di Politeknik Negeri Balikpapan masih sangat efisien sesuai dengan kebutuhan pekerjaan[6]. Meskipun demikian hal tersebut masih belum dapat terlihat dari perhitungan untuk masing-masing ruangan yang ada dilingkungan Politeknik Negeri Balikpapan. Sesuai dengan standar IKE Departemen Pendidikan Republik Indonesia bahwa terdapat pembagian perhitungan untuk IKE ruangan ber-AC dan yang tidak ber-AC, sehingga diperlukan analisa tambahan mengenai kondisi tersebut

\section{Kesimpulan}

Hasil analisa diperoleh bahwa penggunaan konsumsi daya di Politeknik Negeri Balikpapan pada tahun 2016 sebesar 62,7 kWH dan tingkat IKE sebesar 93,096 $\mathrm{kWH} / \mathrm{m}^{2} /$ tahun. Penggunaan konsumsi energi listrik pertahun yang paling tinggi dilingkungan Politeknik Negeri Balikpapan adalah gedung teknik sipil yaitu 33.876,38 $\mathrm{kWH} / \mathrm{tahun}$, sedangakan untuk terendah gedung workshop teknik mesin alat berat yaitu sebesar 28.460,875 kWH/tahun. Dengan demikian, IKE Politeknik Negeri Balikpapan tahun 2016 masih berada di bawah batas aman untuk gedung perkantoran yaitu 240 $\mathrm{kWH} / \mathrm{m}^{2} /$ tahun.

\section{Saran}

Dibutuhkan suatu analisa yang komprehensip yaitu penelitian lanjutan terhadap penggunaan konsumsi listrik untuk masing- masing ruangan disetiap gedung yang ada dilingkungan Politeknik Negeri Balikpapan.

\section{Daftar Pustaka}

[1] J. Custer, "Analisis Audit Energi Di Bengkel Las Politeknik Negeri Bengkalis," in Seminar Nasional Pakar ke 1, 2018, pp. 53-58.

[2] Samsuddin, Suriadi, and Y. Away, "Audit dan Optimasi Energi Listrik Pada Bangunan Kampus Menggunaka Metode Algoritma Genetika," J. Chem. Inf. Model., vol. 53, no. 9, pp. 1689-1699, 2018, doi: 10.1017/CBO9781107415324.004.

[3] J. Teruna, "Audit Energi Awal Melalui Perhitungan Instensitas Konsumsi Energi ( IKE ) Listrik," J. Elektr. Borneo, vol. 5, no. 2, pp. 27-30, 2019.

[4] G. Valentino et al., "Analisis Audit Energi Hotel Sintesa Peninsula Manado," J. Tek. Elektro dan Komput., vol. 8, no. 3, pp. 111120, 2019, doi: 10.35793/jtek.8.3.2019.26563.

[5] A. Machmud and H. Muborak, "Audit Energi dan Peluang Konservasi Energi 
Listrik di PT. Arelsi Karya Sejahtera," Universitas Islam Indonesia, 2019.

[6] F. Xavierus, G. Janardana, and M. Suartika, "Audit Dan Analisis Penghematan Energi Listrik di Hotel Sun Island Bali," $J$. Spektrum, vol. 7, no. 1, pp. 62-68, 2020.

[7] A. Hadi, Z. Abidin, W. M. Faizal, J. T. Elektro, and P. N. Bengkalis, "Analisa Proses Audit Energi Listrik di Gedung D Politeknik Negeri Bengkalis," in Seminar Nasional Teknik Elektro, 2020, vol. 5.

[8] A. W. Biantoro and D. S. Permana, "Analisis Audit Energi Untuk Pencapaian Efisiensi Energi," J. Tek. Mesin, vol. 06, pp. 24-32, 2017. 